\title{
Author Correction: Solution-processed perovskite light emitting diodes with efficiency exceeding $15 \%$ through additive-controlled nanostructure tailoring
}

\author{
Muyang Ban', Yatao Zou1, Jasmine P.H. Rivett ${ }^{2}$, Yingguo Yang ${ }^{3}$, Tudor H. Thomas ${ }^{2}$, Yeshu Tan', Tao Song ${ }^{1}$,
} Xingyu Gao ${ }^{3}$, Dan Credgington (1) ${ }^{2}$, Felix Deschler ${ }^{2}$, Henning Sirringhaus ${ }^{2} \&$ Baoquan Sun (D) ${ }^{1}$

Correction to: Nature Communications https://doi.org/10.1038/s41467-018-06425-5; published online 24 September 2018

The original version of this Article contained an error in the spelling of the author Dan Credgington, which was incorrectly given as Dan Credington. This has now been corrected in both the PDF and HTML versions of the Article.

Published online: 22 February 2019

\begin{abstract}
(c) Open Access This article is licensed under a Creative Commons Attribution 4.0 International License, which permits use, sharing, adaptation, distribution and reproduction in any medium or format, as long as you give appropriate credit to the original author(s) and the source, provide a link to the Creative Commons license, and indicate if changes were made. The images or other third party material in this article are included in the article's Creative Commons license, unless indicated otherwise in a credit line to the material. If material is not included in the article's Creative Commons license and your intended use is not permitted by statutory regulation or exceeds the permitted use, you will need to obtain permission directly from the copyright holder. To view a copy of this license, visit http://creativecommons.org/licenses/by/4.0/.
\end{abstract}

(c) The Author(s) 2019

\footnotetext{
${ }^{1}$ Jiangsu Key Laboratory for Carbon-Based Functional Materials \& Devices, Institute of Functional Nano \& Soft Materials (FUNSOM), Joint International Research Laboratory of Carbon-Based Functional Materials and Devices, Soochow University, 199 Ren'ai Road, Suzhou 215123, People's Republic of China. ${ }^{2}$ Cavendish Laboratory, Department of Physics, University of Cambridge, JJ Thomson Avenue, Cambridge CB3 OHE, UK. ${ }^{3}$ Shanghai Synchrotron Radiation Facility (SSRF), Shanghai Institute of Applied Physics, Chinese Academy of Sciences, 239 Zhangheng Road, Pudong New Area, Shanghai 201204 , China. Correspondence and requests for materials should be addressed to F.D. (email: fd297@cam.ac.uk) or to H.S. (email: hs220@cam.ac.uk) or to B.S. (email: bqsun@suda.edu.cn)
} 